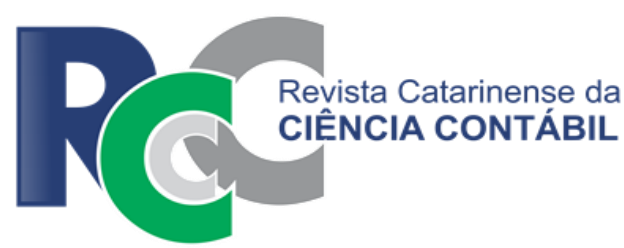

\title{
ADAPTAÇÕES NECESSÁRIAS PARA IMPLANTAÇÃO DO BLOCO K DO SPED FISCAL NAS ORGANIZAÇÕES
}

\section{ADJUSTMENTS REQUIRED FOR DEPLOYMENT OF BLOCK K IN THE SPED FISCAL IN ORGANIZATIONS}

\author{
DÉBORA ALLINE DE MELLO \\ Graduada em Contabilidade pela Universidade do Oeste de Santa \\ Catarina (UNOESC). Pós-graduada em Gestão Tributária pela \\ UNOESC. Endereço: Rua Dirceu Giordani, 696 / Jardim Tarumã / \\ Xanxerê/SC / Brasil. \\ E-mail: debora.allinedm@hotmail.com
}

\section{DAVID RODRIGO PETRY}

Doutorando em Administração pela Universidade do Oeste de Santa Catarina (UNOESC). Professor da UNOESC. Endereço: Rua Cel. Passos Maia, 919 / Centro / Xanxerê/SC / Brasil.

E-mail: david.petry@unoesc.edu.br

\author{
JORGE CARLOS PALUDO \\ Mestre em Administração pela Universidade do Oeste de Santa \\ Catarina (UNOESC). Professor e coordenador do curso de graduação \\ em Ciências Contábeis da UNOESC, em Xanxerê. Endereço: Rua \\ Dirceu Giordani, 696 / Jardim Tarumã / Xanxerê/SC | Brasil. \\ E-mail: jorge.paludo@unoesc.edu.br
}

\section{IEDA MARGARETE ORO}

Doutora em Ciências Contábeis e Administração pela Universidade Regional de Blumenau (FURB). Professora do Curso de Ciências Contábeis e do Mestrado Profissional em Administração da Universidade do Oeste de Santa Catarina (UNOESC). Endereço: Av. Nereu Ramos, 3777D / Seminário / Chapecó/SC / Brasil.

E-mail: ieda.oro@unoesc.edu.br

\section{RESUMO}

O Bloco K é o livro de registro de controle de produção e estoques na versão digital exigido pelo SPED no Brasil. Trata das informações fiscais e tributárias detalhadas dos estabelecimentos das pessoas jurídicas. A exigência desse novo conjunto de informações pelo fisco vem apresentando algumas dificuldades nas organizações para sua implantação. Assim, o objetivo deste artigo visa identificar quais são as principais adaptações administrativas e gerenciais necessárias para a mudança no sistema de controle dos estoques de produtos nas empresas, em relação à implantação do Bloco K no SPED Fiscal. Quanto aos procedimentos metodológicos caracterizase como uma pesquisa descritiva, com abordagem qualitativa, realizada por meio de questionário aplicado no departamento fiscal de cinco empresas catarinenses. Os resultados evidenciam que - Bloco K influência direta e positivamente nas empresas, as quais estão percebendo dificuldades em sua implantação, como problemas com o sistema interno, falhas de configuração, cadastros incompletos e falta de conhecimento para trabalhar com o Bloco K. O estudo permitiu ainda concluir que, mesmo considerando as dificuldades elencadas para a implantação do Bloco K, o sistema traz benefícios que impactam positivamente na gestão das 
empresas, pois fortalece o sistema de controles internos e proporciona maior confiabilidade nas informações geradas. Fatores relacionados ao elevado custo de implantação também foram evidenciados. Esse resultado reforça a importância da empresa estar se aperfeiçoando ao máximo, investindo em conhecimento e tecnologia, para estar preparada para a evolução.

Palavras-chave: SPED Fiscal. Bloco K. Controle de produção e do estoque.

\section{ABSTRACT}

Block $K$ is the record book of production and inventory control in the digital version required by the SPED in Brazil, which deals with the detailed tax information of the establishments of legal entities. The requirement of this new set of information by the tax authorities has shown some difficulties in organizations for its deployment. Thus, this article aims to identify what are the main administrative and managerial adjustments required for the change in the inventory control system of products in the companies in relation to the deployment of block $K$ in the SPED Fiscal. As for the methodological procedures is characterized as a descriptive research with a qualitative approach performed through a questionnaire applied in the tax department of five companies in Santa Catarina. The results show that the block $K$ influences directly and positively in companies that are finding difficulties in its deployment, such as problems with the internal system, configuration failures, incomplete records and lack of knowledge to work with Block K. The study also allowed conclude that even considering the difficulties listed for the deployment of Block K, the system brings benefits that positively impact on company management, as it strengthens the internal control system and it provides greater reliability in information generated. Factors related to the high cost of deployment were also shown. This result reinforces the importance of the company is improving to the most by investing in knowledge and technology, to be prepared for evolution.

Keywords: SPED Fiscal. Block K. Production and inventory control.

\section{INTRODUÇÃO}

Criado pelo ajuste SINIEF n 02, de 1972, o Livro Registro da Produção e do Estoque Modelo 3 já nasceu com a possibilidade de ser substituído por relatórios que demonstrassem a real movimentação dos estoques das empresas. Desde que foi criado, este livro tinha como único propósito informar ao fisco federal e estadual as movimentações de estoque, a árvore de produtos e controlar o custo médio das mercadorias e produtos.

Esse livro fiscal voltou à cena recentemente, em função de ter sido acrescido aos livros obrigatórios do Sistema Público de Escrituração Digital, SPED Fiscal, conforme ajuste SINIEF nº 18, de 11 de outubro de 2013, incorporando mais um bloco de informações ao complexo trabalho de entrega de obrigações já existente (Rocha \& Almeida, 2014).

Instituído pelo Decreto $n^{\circ} 6.022$, de 22 de janeiro de 2007, o projeto do Sistema Público de Escrituração Digital (SPED) faz parte do Programa de Aceleração do Crescimento do Governo Federal (PAC) 2007-2010 e se constitui em mais um avanço na informatização da relação entre o fisco e os contribuintes. Esse decreto iniciou com três grandes projetos: Escrituração Contábil Digital, Escrituração Fiscal Digital e a NFe Ambiente Nacional.

Entre os projetos do SPED, a Escrituração Fiscal Digital, EFD, constitui-se de um conjunto de escriturações de documentos fiscais e de outras informações de interesse dos fiscos das unidades federadas e da Secretaria da Receita Federal do Brasil, bem como de registros de apuração de impostos referentes às operações e prestações praticadas pelo contribuinte. Esse arquivo deverá ser assinado digitalmente e transmitido, via Internet, ao ambiente SPED (Receita Federal do Brasil, 2015).

Com essa nova obrigatoriedade estabelecida pelo SPED, incluindo o Livro Registro de controle da Produção e do Estoque no SPED Fiscal, a receita federal passará a ter acesso à movimentação completa de cada item do estoque, além de conhecer o processo produtivo de cada empresa. Oliveira (2014) e Rocha e Almeida (2014) argumentam que a inclusão do Bloco 
K possibilitará ao agente fiscalizador o cruzamento qualitativo dos saldos apurados eletronicamente pelo Sped com os informados por meio do saldo do inventário das indústrias.

Esse bloco destina-se a apresentar informações mensais da produção e respectivo consumo de insumos, bem como do estoque escriturado, relativos às disposições contidas no Ajuste SINIEF 8, de 2 de outubro de 2015. Se a empresa possui em algum de seus estabelecimentos qualquer dos processos que caracterizam uma industrialização, segundo a legislação de ICMS e de IPI, e cujos produtos resultantes sejam tributados pelo ICMS ou IPI, mesmo que de alíquota zero ou isento, se possuir CNAE, mesmo que secundário, das divisões 10 a 32; e se a receita bruta de venda de mercadorias de todos os seus estabelecimentos no território nacional, industriais ou não, excluídas as vendas canceladas, as devoluções de vendas e os descontos incondicionais concedidos, igual ou superior a $R \$ 300.000 .000,00$, no segundo exercício anterior ao início de vigência da obrigação, então, deverá apresentar o Bloco K a partir de 01/01/2016 (Ajuste Sinief Confaz 8, 2015).

Para os demais estabelecimentos atacadistas classificados nos grupos 462 a 469 da Classificação Nacional de Atividades, e os equiparados a industrial, a obrigatoriedade de escriturar o Bloco $\mathrm{K}$ foi a partir de $1^{\circ}$ de janeiro de 2018.

Portanto, os registros a serem informados no Bloco $\mathrm{K}$ correspondem aos dados das fichas técnicas dos produtos, das perdas ocorridas no processo produtivo, das ordens de produção, dos insumos consumidos e da quantidade produzida, inclusive das industrializações, efetuadas em terceiros.

Nesse contexto, para atender às obrigações fiscais as empresas precisaram investir em educação continuada e em sistemas que possibilitem a apuração e integração dos custos de produção implementando um controle de produção confiável para cumprir o prazo oferecido pelo governo. As empresas precisaram se adequar e, em alguns casos, reestruturar os seus procedimentos de trabalho.

Concomitantemente, a preocupação das organizações quanto à utilização de sistemas de informações confiáveis vem aumentando. Somasundaram e Shrivastava (2011) destacam que o controle e armazenamento de informações transformou-se em uma tecnologia altamente sofisticada, possibilitando uma diversidade de soluções para proteção, segurança e otimização da informação digital, no entanto, a utilização dessas ferramentas ainda é pouco explorada.

Segundo Young (2009), na implementação de um projeto SPED, várias áreas, processos e sistemas das empresas devem ser revistos, alterados ou até mesmo criados, objetivando-se disponibilizar para o fisco as informações requeridas pela nova legislação em vigor.

Com a implantação do Bloco K do SPED fiscal, houve mudança na forma de se registrar as operações contábeis. Como é um decreto recente e até então pouco difundido, principalmente em fontes literárias, há uma grande procura por informações claras e específicas sobre o assunto. Para auxiliar nesse processo de adequação ao SPED é necessário que sejam apontados os principais pontos em que há dificuldades, para que os órgãos competentes possam fornecer os devidos esclarecimentos, buscando-se, assim, nas empresas pesquisadas, identificar quais os fatores determinantes para obter êxito no processo de implantação e adaptação ao Bloco K, que possam servir de base para as demais empresas que ainda não implantaram ou não utilizam o sistema.

Diante desse contexto surge a questão que norteará o desenvolvimento deste estudo: quais as principais adaptações decorrentes da implantação do Bloco K no SPED Fiscal na gestão operacional das empresas?

Em decorrência do questionamento proposto, o objetivo deste estudo é verificar as principais alterações e adequações decorrentes da implantação do Bloco K no SPED Fiscal, na gestão operacional.

Assim, esta pesquisa justifica-se pela possibilidade de contribuir para o conhecimento das dificuldades que estão sendo enfrentadas pelas empresas com a implementação e adaptação ao novo sistema, permitindo a ampliação dos conhecimentos a cerca do que é o Bloco $\mathrm{K}$ e também dos pontos positivos e negativos que esse sistema trouxe nas empresas pesquisadas inferindo novas informações que poderão contribuir para o desenvolvimento de futuras pesquisas relacionadas a essa temática.

O trabalho está estruturado iniciando com esta introdução. Na sequência, faz-se uma incursão teórica apresentando de forma geral os conceitos, aspectos legais e obrigatoriedades. 
Envolvem temas referentes aos prazos diferenciados de entrega por atividade e faturamento, informações base para o Bloco K, penalidades aplicáveis ao SPED, controle de custos, organização e adaptação das informações para o Bloco K.

Em seguida, apontam-se os procedimentos metodológicos da pesquisa, os resultados com a interpretação das informações coletadas por meio de questionário, e, por fim, as conclusões e recomendações pertinentes ao tema abordado.

\section{FUNDAMENTAÇÃO TEÓRICA}

Diversas alterações e adaptações serão necessárias para atender ao Bloco K introduzido no SPED Fiscal para as empresas. O entendimento do que é o Bloco $\mathrm{K}$ não pode ser tratada simplesmente pela interpretação da regra legal, visto que vai muito além desse contexto técnico importante. Deve abranger a compreensão sistêmica da organização e os impactos que possam advir.

Apresenta-se, nesta seção, o desenvolvimento do trabalho, uma breve revisão da literatura que servirá como base para o progresso e análise do estudo, fundamentando e explanando as bases teóricas concernentes ao assunto abordado.

\subsection{Prazos diferenciados de entrega por atividade e faturamento}

Com a publicação do Ajuste SINIEF 8/2015, no DOU de 08/10/2015, foram estabelecidos prazos diferenciados de entrega por atividade e faturamento, conforme a Classificação Nacional de Atividades Econômicas, CNAE.

A partir de $1^{\circ}$ de janeiro de 2016: Para os estabelecimentos industriais classificados nas divisões 10 a 32 da CNAE pertencentes à empresa com faturamento anual igual ou superior a $\mathrm{R} \$ 300.000 .000,00$, dentre as quais destacam-se: Fabricação de Produtos Alimentícios, CNAE seção 10; Fabricação de Produtos Têxteis, CNAE seção 13; Fabricação de Produtos de Madeira, CNAE seção 16; Fabricação de Celulose, Papel e Produtos de Papel CNAE seção 17; Metalurgia, CNAE seção 24; Fabricação de Produtos de Metal, exceto Máquinas e Equipamentos, CNAE seção 25; Fabricação de Equipamentos de Informática, Produtos Eletrônicos e Ópticos, CNAE seção 26; Fabricação de Máquinas e Equipamentos, CNAE seção 28; Fabricação de Veículos Automotores, Reboques e Carrocerias, CNAE seção 28; e Fabricação de Outros Equipamentos de Transporte, exceto Veículos Automotores , CNAE seção 30.

A partir de $1^{\circ}$ de janeiro de 2017, cabe a entrega do registro do Bloco $\mathrm{K}$ para os estabelecimentos industriais classificados nas divisões 10 a 32 da CNAE pertencentes à empresa com faturamento anual igual ou superior a $\mathrm{R} \$ 78.000 .000,00$.

A partir de $1^{\circ}$ de janeiro de 2018, para os demais estabelecimentos industriais e equiparados a industrial, bem como estabelecimentos atacadistas classificados nos grupos 462 a 469 da CNAE, dentre os quais destacam-se:

a) Comércio Atacadista de Matérias Primas Agrícolas e Animais Vivos, CNAE seção 462 ;

b) Comércio Atacadista de Máquinas, Aparelhos e Equipamentos, exceto de Tecnologias de Informação e Comunicação, CNAE seção 466.

De acordo com o $\S 8^{\circ}$ da Cláusula Segunda do Ajuste SINIEF nº 8 (2015), considera-se estabelecimento industrial aquele que possui qualquer dos processos que caracterizam uma industrialização, nos termos da legislação do ICMS e do IPI, em que os produtos resultantes estejam sujeitos a esses tributos, mesmo com alíquota zero ou isenção.

Por fim, as alterações introduzidas pelo Ajuste SINIEF $n^{\circ} 8$ (2015), para fins de faturamento, deverão ser observadas. Considera-se faturamento a receita bruta de venda de mercadorias de todos os estabelecimentos da empresa no território nacional, industriais ou não, excluídas as vendas canceladas, as devoluções de vendas e os descontos incondicionais concedidos. O período de referência do faturamento deverá ser o segundo exercício anterior ao início de vigência da obrigação. 
Os contribuintes que estão obrigados a prestar o Bloco $\mathrm{K}$ devem estar atentos, pois, a não apresentação, omissão ou inexatidão de informações poderá acarretar penalidades.

\subsection{Informações base para o Bloco K}

As informações do Bloco K são compostas por informações sobre os materiais dentro da empresa, desde a posição do estoque aos insumos para produção. A inclusão do Bloco K, que se encontra na Seção 7 do Capítulo III, Registro da EFD ICMS/IPI, destina-se a prestar informações mensais da produção e respectivo consumo de insumos, bem como do estoque escriturado:

\begin{tabular}{|c|l|c|}
\hline Bloco & \multicolumn{1}{|c|}{ Descrição } & Reg. \\
\hline $\mathrm{K}$ & Abertura do Bloco K & $\mathrm{K} 001$ \\
\hline $\mathrm{K}$ & Período de Apuração do ICMS/IPI & $\mathrm{K} 100$ \\
\hline $\mathrm{K}$ & Estoque Escriturado & $\mathrm{K} 200$ \\
\hline $\mathrm{K}$ & Outras Movimentações Internas entre Mercadorias & $\mathrm{K} 220$ \\
\hline $\mathrm{K}$ & Itens Produzidos & $\mathrm{K} 230$ \\
\hline $\mathrm{K}$ & Insumos Consumidos & $\mathrm{K} 235$ \\
\hline $\mathrm{K}$ & Industrialização Efetuada por Terceiros - Itens Produzidos & $\mathrm{K} 250$ \\
\hline $\mathrm{K}$ & Industrialização em Terceiros - Insumos Consumidos & $\mathrm{K} 255$ \\
\hline $\mathrm{K}$ & Encerramento do Bloco K & $\mathrm{K} 990$ \\
\hline
\end{tabular}

Figura 1. Composição do Bloco $\mathrm{K}$

Fonte: Ajuste SINIEF n 2/2009, cláusula primeira, $\S \S 3^{\circ}$, VII, e 70; Minuta do guia Prático da EFD, versão 2.0.14.

Conforme Ajuste SINIEF $n^{\circ} 17 / 2014$, que deu nova redação ao $\S 7^{\circ}$ da cláusula terceira do Ajuste SINIEF $n^{\circ}$ 2/2009, que dispõe sobre a Escrituração Fiscal Digital (EFD), que se encontra na Seção 7 do Capítulo III, Registro da EFD-ICMS/IPI, esse novo bloco é composto pelos seguintes registros:

- Registro K001 - Abertura do Bloco K. Deve ser gerado para abertura do Bloco K, indicando se há registros de informações no bloco:;

- Registro K100 - Período de Apuração do ICMS/IPI. Informar o período de apuração do ICMS ou do IPI, prevalecendo os períodos mais curtos. Os contribuintes com mais de um período de apuração no mês declaram um registro K100 para cada período no mesmo arquivo;

- Registro K200 - Estoque Escriturado. Para cada período de apuração informado no K100, deve ser escriturado o estoque final por tipo (mercadorias para revenda, matérias primas, embalagens, produtos em processo, produtos acabados, subprodutos e outros insumos);

- Registro K220 - Outras Movimentações Internas entre Mercadorias. Informar a movimentação interna entre mercadorias, que não se enquadre nas já informadas nos Registros K230 e K235: produção acabada e consumo no processo produtivo, respectivamente.

- Registro K230 - Itens Produzidos. Informar a produção de produto em processo e acabado.

- Registro K235 - Insumos Consumidos. Informar o consumo de mercadoria no processo produtivo, vinculado ao produto resultante informado no Registro K230Itens Produzidos.

- Registro K250 - Industrialização Efetuada por Terceiros - Itens Produzidos. Informar os produtos que foram industrializados por terceiros e sua quantidade.

- Registro K255 - Industrialização em Terceiros - Insumos Consumidos. Informar a quantidade de consumo do insumo que foi remetido para ser industrializado em terceiro, vinculado ao produto resultante informado no Registro K250. 
- Registro K990 - Encerramento do Bloco K. Identificar o encerramento do Bloco K e informar a quantidade de linhas existentes no bloco.

Relacionadas ao controle do estoque da empresa, para Martins (2015), essas informações se restringirão ao processo produtivo e às quantidades de matéria-prima, insumos, embalagem, produto acabado, produção de terceiros, insumos consumidos nesse processo, reclassificação de produtos, insumos substituídos no processo, dentre outros.

Segundo Leão (2015) é necessário analisar e planejar detalhadamente a adequação dos processos de gestão da produção às exigências do fisco, estudar todos os requisitos do Bloco $\mathrm{K}$, mapear cada detalhe dos processos de industrialização, terceirização e estocagem, avaliar o software que adotará para atender às exigências, preparar e treinar sua equipe interna na operação e nos registros de informações, fazer testes para confirmar se as informações coletadas no sistema correspondem à realidade.

A visão integrada dessa obrigação, para Fernandes (2015), contribui para uma eficiente gestão tributária, que tem como objetivo não desperdiçar recursos, já que o estoque concentra a maior energia estratégica da empresa, pela decisão de comprar barato ou a prazo e vender a prazo ou a vista.

Entretanto, Alves (2015) aponta como um aspecto importante que será preciso mencionar, por ordem de produção, todos os itens fabricados e os itens consumidos, com as respectivas quantidades e datas, fabricadas pelo próprio estabelecimento ou por terceiros. É imprescindível que seja implantado e parametrizado o sistema da empresa para a obtenção desses dados.

De acordo com Bompan (2015, p.12):

A movimentação de ajuste de estoque, ajustes de inventário, movimentação de consumo interno de insumos não apropriados a ordens de produção, não serão escriturados no Bloco K, essas movimentações devem ser escrituradas em outro bloco, pois deve-se emitir uma nota fiscal para estas saídas.

Essas informações serão disponibilizadas pelo contribuinte, desta forma, deverão ficar atentos quanto a sua estrutura, pois o fisco terá condições de controlar o estoque em paralelo a empresa, tornando as empresas escravas do que informarem.

Jesus (2015, p. 2), observa que:

A Receita Federal terá registrada no Bloco K do SPED Fiscal, as quantidades produzidas e os insumos consumidos em cada material intermediário ou produto acabado, podendo através desta informação, projetar o estoque de matéria-prima e de produto acabado do contribuinte, e as informações de industrialização efetuada por terceiros.

Devido à grande complexidade desse registro, Martins (2015) observa que é imprescindível para empresas uma solução tecnológica que tenha estrutura para o cumprimento da obrigação legal. Devem registrar todas as operações, com uma folha para cada espécie, marca, tipo e modelo da mercadoria, além de entender os registros do bloco e visualizar como atendê-los, com base nas informações existentes no seu sistema operacional.

\subsection{Penalidades aplicáveis ao SPED}

A entrega do Bloco K será realizada, acompanhada do SPED ICMS/IPI, no dia 25 do mês subsequente ao da apuração (Receita Federal, 2015).

Dessa forma, se não cumprido o prazo estabelecido pela Receita Federal será aplicada a Lei $n^{\circ} 12.873$, de 24 de outubro de 2013, estabelece as seguintes penalidades: $O$ sujeito passivo que deixar de cumprir as obrigações acessórias exigidas nos termos do art. 16 da Lei $n^{\circ}$ 9.779, de 19 de janeiro de 1999, ou que as cumprir com incorreções ou omissões será intimado para cumpri-las ou para prestar esclarecimentos relativos a elas nos prazos estipulados pela Secretaria da Receita Federal do Brasil e sujeitar-se-á às seguintes multas conforme redação dada pela Lei $n^{\circ} 12.873$, de outubro de 2013: 
a) por apresentação extemporânea: $R \$ 500,00$ (quinhentos reais) por mês calendário ou fração, relativamente às pessoas jurídicas que estiverem em início de atividade ou que sejam imunes ou isentas ou que, na última declaração apresentada, tenham apurado lucro presumido ou pelo Simples Nacional; $R \$ 1.500,00$ (mil e quinhentos reais) por mês calendário ou fração, relativamente às demais pessoas jurídicas; $R \$ 100,00$ (cem reais) por mês calendário ou fração, relativamente às pessoas físicas.

b) por não cumprimento à intimação da Secretaria da Receita Federal do Brasil para cumprir obrigação acessória ou para prestar esclarecimentos nos prazos estipulados pela autoridade fiscal: $\mathrm{R} \$ 500,00$ (quinhentos reais) por mês calendário.

c) por cumprimento de obrigação acessória com informações inexatas, incompletas ou omitidas: $3 \%$, não inferior a $\mathrm{R} \$ 100,00$ (cem reais) do valor das transações comerciais ou das operações financeiras, próprias da pessoa jurídica ou de terceiros em relação aos quais seja responsável tributário, no caso de informação omitida, inexata ou incompleta; $1,5 \%$, não inferior a $R \$ 50,00$ (cinquenta reais) do valor das transações comerciais ou das operações financeiras, próprias da pessoa física ou de terceiros em relação aos quais seja responsável tributário, no caso de informação omitida, inexata ou incompleta.

d) na hipótese de pessoa jurídica optante pelo Simples Nacional, os valores e o percentual serão reduzidos em $70 \%$ (setenta por cento). A multa será reduzida à metade, quando $a$ obrigação acessória for cumprida antes de qualquer procedimento de ofício.

Joaquim (2015, p. 1) observa que:

Finalmente a Receita atendeu o clamor dos empresários, profissionais e entidades de classes pela cobrança exorbitante que era anteriormente de $\mathrm{R} \$ 5.000,00$ por mês ou fração pela não entrega nos prazos os programas do SPED e não distinguindo o porte das empresas e a sua capacidade contributiva, que, aliás, são selecionados pelo fisco para fins arrecadatório, como por exemplo para fins de lucro real como: bancos, factoring, pessoas jurídicas que usufruam de incentivos fiscais, faturamento bruto no ano calendário anterior etc.

É necessário cuidado com a elaboração e entrega de todos os programas do SPED, pois o Fisco já possui sistemas de controles eletrônicos para aplicação das referidas penalidades de forma mais eficiente.

\subsection{Controle de custos e seus custos de implantação}

Para que a implantação do custo contábil seja eficiente, será necessário realinhamento interno no que diz respeito a mudanças de cultura, como também o apoio de todos os colaboradores ligados direta ou indiretamente à produção. Assim, eventuais diferenças entre os saldos poderão ser justificados, caso contrário será configurado como sonegação fiscal e sofrerá assim as penalidades, conforme a Lei $n^{\circ} 12.873$, de 24 de outubro de 2013, trazidas por essa nova realidade.

Em um ambiente de novas normas contábeis e de controle e fiscalização eletrônica, os contribuintes devem efetuar um trabalho detalhado de revisão da estrutura de custos e de configuração do sistema de gestão empresarial - ERP e de gestão fiscal (Rocha, 2012, p. 7).

A responsabilidade pelas informações geradas pela Contabilidade de Custos não é exclusiva do Contador. Envolve profissionais da área fiscal, custos, e das demais áreas direta ou indiretamente ligadas com a produção.

Com tanta informação repassada pelos contribuintes, o Fisco poderá realizar o cruzamento quantitativo dos saldos apurados eletronicamente pelo SPED com os informados pelas empresas, por intermédio do inventário.

As informações para o Bloco $\mathrm{K}$ no arquivo do SPED Fiscal não envolvem valores 
monetários, apenas as quantidades dos produtos.

Dessa forma, para Jesus (2015), esse controle visa a erradicar eventuais diferenças nos saldos, se não justificados, o que pode configurar sonegação fiscal, contribuir para a extinção a prática de nota fiscal espelhada, calçada, dublada, subfaturada ou meia nota, além da manipulação das quantidades de estoques por ocasião do inventário físico.

Apesar de o fisco exigir informações detalhadas a seu favor, é fato que indiretamente as organizações também são beneficiadas pelas exigências nos controles de custo. $O$ simples fato de conseguir mensurar o custo do processo produtivo permite às organizações traçarem novas estratégias e buscarem novos mercados, a fim de melhorar seu desempenho.

No entanto, esse processo de implantação ainda possui um fator que deve ser analisado com bastante cuidado. De acordo com Passos (2010), uma das principais críticas à implantação do SPED refere-se justamente aos custos para sua implantação e à adequação às novas regras estabelecidas por esse sistema. As organizações apresentam certa cautela com relação aos investimentos realizados, visto que, a curto prazo, somente o governo é beneficiado por esse sistema.

Apesar disso, a inserção do SPED ainda é muito recente nas organizações. Mais recente ainda é o Bloco K, cuja implantação ainda está no princípio. Será no decorrer do início da década de 2020 que sua consolidação poderá ser melhor mensurada e analisada comparativamente, pois aí sim os efetivos custos de implantação serão conhecidos. Nesse período, será possível também identificar os primeiros benefícios que o Bloco $\mathrm{K}$ trará para as empresas.

\subsection{Controle, organização e adaptação das informações para o Bloco K}

Nas últimas décadas o controle e o armazenamento de informações transformou-se em uma tecnologia altamente sofisticada. Possibilitam uma diversidade de soluções para proteção, segurança e otimização da informação digital (Somasundaram \& Shrivastava, 2011). Aliada a essa tecnologia, o Bloco K surge como ferramenta de controle, tanto para as organizações como para o fisco. Ele não pode ser visto apenas como uma obrigação acessória a ser preenchida de maneira a evitar multas administrativas, mas sim como uma demanda da visão integrada de todo o grupo envolvido.

A criação de estratégias, formalizadas por meio de um planejamento bem estruturado, é um processo que leva em conta os pontos fortes e fracos das organizações, assim como as ameaças e oportunidades do meio ambiente, para produzir e articular os resultados, estabelecendo objetivos, estratégias e ações na forma de um sistema integrado de decisões que possibilitem aumento de competitividade empresarial (Cruz, Librelotto, Ferroli, Bonatti \& Zanin, 1998).

Nesse sentido, os sistemas de informações devem ser distinguidos do nível estratégico para altos gerentes, que enfocam os problemas da tomada de decisão. Esses primeiros podem ser usados por todos os níveis da organização e ainda são de maior alcance e profundidade que outras classes de sistemas.

Para Bompan (2015), a responsabilidade é conjunta entre a equipe de planejamento de produção, a equipe contábil, vinculada especificamente com custos, e a equipe tributária, fiscal e jurídica. Contudo, para Gomes (2014), diante da abertura de segredos de produção, as empresas serão diretamente impactadas no que tange à necessidade de aperfeiçoamento da qualidade nos controles relacionados aos estoques e à produção. A ausência ou falta de qualidade nesses controles poderá expor as empresas a questionamentos ou mesmo a autuações pelo fisco.

Para Jesus (2015, p. 1):

O processo produtivo industrial nem sempre é executado com base em ordem de produção, alguns produtos pelas suas características tem fluxo continuo de produção e outros são de longa duração, as vezes ultrapassam o exercício fiscal, outros são produzidos para estoques e permanecem sem alterações, outros são produzidos por encomenda com especificação técnicas definidas pelos clientes. 
Devido a essa vasta cadeia produtiva das indústrias, Gomes (2014) enfatiza que a medida mais saudável é contar com o auxílio de profissionais experientes e comprometidos para analisar e revisar os dados levantados, a fim de evitar incoerência nas informações repassadas ao fisco por meio do Bloco K do SPED Fiscal, evitando atuação fiscal.

A Instrução Normativa $n^{\circ}$ 86/2001 da Secretaria da Receita Federal dispõe que, as pessoas jurídicas que utilizarem sistemas de processamento eletrônico de dados para registrar negócios e atividades econômicas ou financeiras, escriturar livros ou elaborar documentos de natureza contábil ou fiscal, ficam obrigadas a manter, à disposição da SRF, os respectivos arquivos digitais e sistemas, pelo prazo decadencial previsto na legislação tributária.

Para atender à IN-86 as empresas devem ter condições de poder entregar os arquivos solicitados pela fiscalização dentro do prazo solicitado.

Para Fernandes (2015, p. 1):

Como a quantidade e a diversidade de arquivos são grandes e o prazo de entrega é muito curto, a empresa deve preferivelmente preparar os arquivos com antecedência, ou seja, deixar os arquivos preparados, e devidamente validados, antes de uma possível fiscalização.

Para que a empresa possa ter certeza de que seus arquivos estão 100\% corretos e de acordo com as especificações exigidas, Bompan (2015) destaca que há necessidade de fazer uma série de testes de validação antes de serem entregues para a fiscalização. Esses testes devem ser feitos com bastante antecedência a fim de que haja tempo suficiente para fazer as eventuais correções.

No mesmo panorama, Gomes (2014) defende que o sistema da empresa deve dispor de um programa de geração dos arquivos que possa transformar os dados no formato exigido pela legislação, para que possam em seguida ser validados, ou seja, para atender à IN-86 a empresa deve ter funcionários capacitados e investir em um sistema operacional adequado a entregar os arquivos solicitados pela fiscalização dentro do prazo solicitado, para evitar problemas com o fisco e gerir a empresa de forma eficaz.

\section{METODOLOGIA}

A metodologia objetiva captar e analisar as características de um conjunto de regras básicas que busca desenvolver evidências observáveis, de modo a obter, organizar, sistematizar e produzir conhecimento. Segundo Gil (2010, p. 261), metodologia "é a organização das partes ou dos elementos que forma um todo".

A abordagem do problema caracteriza-se de forma qualitativa. Para Richardson (1999), essa metodologia diferencia-se tanto nas formas de coleta de informações, quanto no seu tratamento, por meio de técnicas de análise de conteúdo, desde as mais simples até as mais complexas.

A pesquisa caracteriza-se ainda como descritiva relacional. Cooper e Schindler (2011) destacam que, por meio da pesquisa descritiva, busca-se identificar a frequência com que ocorre determinado fenômeno, a relação e conexão que possui com outros, além de sua natureza e características. Pesquisas dessa natureza possuem a característica de observar, registrar, analisar e correlacionar fatos ou fenômenos sem que os mesmos sejam manipulados (Cooper \& Schindler, 2011).

Do ponto de vista dos procedimentos técnicos, a pesquisa caracteriza-se como levantamento. Para isso, a ferramenta utilizada para coleta de dados neste estudo foi questionário estruturado, tendo em vista que se constitui numa das mais importantes técnicas para a obtenção de dados nas pesquisas sociais (Gil, 2010). O autor complementa afirmando que:

Pode-se definir questionário como a técnica de investigação composta por um número mais ou menos elevado de questões apresentadas por escrito às pessoas, tendo por 
objetivo o conhecimento de opiniões, crenças, sentimentos, interesses, expectativas, situações vivenciadas, etc. (Gil, 2010, p.125).

Os questionários foram encaminhados via e-mail a 6 empresas, aos cuidados dos profissionais que atuam no departamento fiscal. O questionário foi composto por 14 perguntas, 3 perguntas abertas e 11 fechadas. Para Gil (2010), nas perguntas abertas os entrevistados discorrem sobre opiniões próprias, enquanto nas fechadas respondem baseados numa lista de alternativas previamente oferecidas.

Após a efetivação da coleta de dados por meio de questionários, revisão bibliográfica dos temas ligados à pesquisa, foi realizada a condensação de dados extraídos do resumo das respostas. Segundo Marconi (2009), é por meio da análise dos dados que se encontram os detalhes decorrentes do trabalho estatístico, com a finalidade de buscar as respostas às indagações do estudo, assim como esclarecer as relações necessárias entre os dados obtidos.

A análise dos dados foi realizada por método comparativo, definido como "a comparação de um determinado número de organizações a fim de estabelecer relações entre suas características" (Gil, 2010, p. 18).

Assim, a próxima seção traz as análises realizadas no estudo bem como os principais resultados quanto à percepção dos respondentes sobre a implantação do Bloco $\mathrm{K}$ nas organizações.

\section{ANÁLISE DE RESULTADOS}

O questionário foi idealizado com perguntas intuitivas e práticas para obter respostas de fácil entendimento. Adicionalmente, constatou-se que a maioria possuía e-mail, o que definiu a forma de comunicação, tanto de envio como de recepção dos questionários. Assim, iniciou-se questionando se o respondente tem ciência da necessidade da implantação do Bloco K no Sistema Público de Escrituração Digital - ICMS/IPI, conforme demonstrado na Tabela 1.

Tabela 1

A empresa tem ciência da obrigatoriedade de apresentação do Bloco K

\begin{tabular}{ccc|cc}
\hline \multirow{2}{*}{ Opção } & \multicolumn{2}{c|}{ Ciência da obrigatoriedade do Bloco K } & \multicolumn{2}{c}{ Cumprimento do prazo para apresentação } \\
\cline { 2 - 5 } & Entrevistados & Frequência & Entrevistados & Frequência \\
\hline Sim & 5 & $100 \%$ & 4 & $80 \%$ \\
Não & 0 & $0 \%$ & 1 & $20 \%$ \\
TOTAL & 5 & $\mathbf{1 0 0 \%}$ & $\mathbf{5}$ & $\mathbf{1 0 0 \%}$ \\
\hline
\end{tabular}

Nota. Fonte: Dados da Pesquisa.

Verifica-se na Tabela 1 que todos os respondentes já possuem ciência da obrigatoriedade de apresentação do Bloco K. Concomitantemente, questionou-se se a empresa está se organizando a fim de atender aos prazos estabelecidos pela legislação. Conforme apresentado na Tabela 1, verifica-se que $20 \%$ dos respondentes não conseguirão cumprir a exigência de apresentação do Bloco $\mathrm{K}$ no prazo, porém, a maioria, ou seja $80 \%$ responderam que conseguirão cumprir tal a exigência.

Dentre as 5 empresas entrevistadas, 40\% classificam-se como estabelecimentos industriais classificados nas divisões 10 a 32 da CNAE (indústrias de transformação), pertencentes à empresa com faturamento anual igual ou superior a $R \$ 78 \cdot 000 \cdot 000,00$. Teve sua obrigatoriedade a partir de $1^{\circ}$ de janeiro de 2017 . 60\% classificam-se para os demais estabelecimentos industriais e equiparados a industrial, bem como estabelecimentos atacadistas classificados nos grupos 462 a 469 da CNAE, com obrigatoriedade a partir de $1^{\circ}$ de janeiro de 2018. 
Tabela 2

Classificação em que a empresa se enquadra

\begin{tabular}{|c|c|c|}
\hline Classificação da Empresa & Entrevistados & Frequência \\
\hline $\begin{array}{l}\text { Estabelecimentos industriais classificados nas divisões } 10 \text { a } 32 \text { da CNAE } \\
\text { (indústrias de transformação) pertencentes à empresa com faturamento } \\
\text { anual igual ou superior a } R \$ 300.000 .000,00 \text {; }\end{array}$ & 0 & $0 \%$ \\
\hline $\begin{array}{l}\text { Estabelecimentos industriais de empresa habilitada ao Regime Aduaneiro } \\
\text { Especial de Entreposto Industrial sob Controle Informatizado (Recof) ou a } \\
\text { outro regime alternativo; }\end{array}$ & 0 & $0 \%$ \\
\hline $\begin{array}{l}\text { Estabelecimentos industriais classificados nas divisões } 10 \text { a } 32 \text { da CNAE } \\
\text { (indústrias de transformação) pertencentes à empresa com faturamento } \\
\text { anual igual ou superior a } R \$ 78.000 .000,00 ;\end{array}$ & 2 & $40 \%$ \\
\hline $\begin{array}{l}\text { Demais estabelecimentos industriais, Estabelecimentos atacadistas } \\
\text { classificados nos grupos } 462 \text { a } 469 \text { da CNAE }\end{array}$ & 3 & $60 \%$ \\
\hline
\end{tabular}

Nota. Fonte: Dados da Pesquisa.

Os resultados apresentam-se dessa forma devido às organizações não se caracterizarem como sendo de grande porte.

$\mathrm{Na}$ sequência, questionou-se os profissionais se o sistema operacional que utilizam nos processos de produção e controle de estoques está preparado para apresentar as informações requeridas nos registros do Bloco K. Os resultados são apresentados na Tabela 3.

Tabela 3

Adequação do sistema ERP ao Bloco K

\begin{tabular}{ccc}
\hline & Entrevistados & Frequência \\
\hline Sim & 4 & $80 \%$ \\
Não & 1 & $20 \%$ \\
\hline
\end{tabular}

Nota. Fonte: Dados da Pesquisa.

Verifica-se dentre os respondentes que apenas um possuía um sistema que não atende aos requisitos do Bloco $\mathrm{K}$, ou seja, que $80 \%$ dos entrevistados, afirmam que os sistemas utilizados para controle de estoque garantem o suporte necessário para a entrega da obrigação.

Do ponto de vista da maioria das empresas, os sistemas de informação hoje são considerados como um recurso estratégico para as empresas, para, consequentemente, buscarem e gerenciarem as informações, e, assim, garantir suporte para a tomada de decisão.

Com relação ao respondente que afirmou que seu sistema não possui capacidade para que os auxiliem na gestão da empresa, enfatiza-se que esse dado deve-se pelo fato de se tratar de uma empresa familiar e não veem nesse momento a aquisição de um sistema operacional como instrumento essencial, pois dizem possuir seus próprios meios de controle.

Questionou-se se o volume de informações acrescidas com o registro do Bloco K poderão acarretar dificuldades na geração do arquivo para transmissão à Receita Federal. Todos responderam que os detalhes exigidos para a apresentação são muitos e que as dificuldades são inevitáveis.

Os respondentes destacam ainda que as dificuldades ocorrem devido às grandes modificações e formas de interpretação, pois, na maioria das vezes, as leis são expostas aos usuários, mas não se detalha a sua funcionalidade ou a sua aplicabilidade. O tempo para adaptação é um grande vilão para o preenchimento do Bloco K. Corrobora com o disposto por Alves (2015) de que a necessidade de mensuração da produção por Ordens de Produção pode dificultar o processo, visto que as adequações e ajustes do que vinham fazendo até então são muito trabalhosos e a maioria das empresas deixou para se adequar no último momento. Isso gerou transtornos.

Por meio da pesquisa contatou-se ainda que os profissionais não acreditam que esse novo sistema lhes proporcione menos burocracia e redução da carga de trabalho. Pelo contrário, enfatizaram que no primeiro momento haverá um aumento considerável de trabalho, em virtude 
das exigências e, como o cruzamento das informações está cada vez mais consistente, a atenção tende ser mais fortemente exigida.

O segundo respondente destaca:

É um novo desafio que deve ser cumprido, lhes repassando informações e adequando seus sistemas de acordo com o layout exigido. $O$ mesmo pode-se dizer em relação à burocracia, pois, não diminuirá no princípio, porque, mesmo que seja tudo digitalizado ainda é necessário realizar a conferência de todos os dados e informações que devem ser repassadas ao fisco.

Ao serem questionados se para atender às novas regras do Bloco $\mathrm{K}$ estão utilizando assessoria de empresa especializada, para dar suporte aos colaboradores, a fim de atender às necessidades e prioridades da empresa em relação à exigência, todos destacaram que ainda é cedo para isso, e optaram por realizar o processo de adaptação inicialmente com ferramentas e recursos próprios. No entanto, o que preocupa as organizações e converge para aqueles fatores apontados por Bompan (2015) e Gomes (2014) é a exposição de segredos de produção. Esse fator ainda deve ser amplamente discutido internamente, a fim de que referidas informações não se tornem públicas com a implantação do Bloco K.

O sétimo questionamento buscou identificar se foram disponibilizados aos colaboradores treinamentos direcionados ao uso dos sistemas operacionais dos processos internos para o correto preenchimento dos dados das fichas técnicas dos produtos, das perdas ocorridas no processo produtivo, das ordens de produção, dos insumos consumidos e da quantidade produzida, inclusive das industrializações, dados esses obrigatórios a ser apresentados no Bloco K. Os resultados são demonstrados na Tabela 4.

Tabela 4

Disponibilização de treinamento aos colaboradores direcionados ao uso dos sistemas operacionais dos processos internos para o correto preenchimento dos dados das fichas técnicas dos produtos

\begin{tabular}{ccc}
\hline & Entrevistados & Frequência \\
\hline Sim & 4 & $80 \%$ \\
Não & 1 & $20 \%$ \\
\hline
\end{tabular}

Nota. Fonte: Dados da Pesquisa.

Verifica-se que $80 \%$ disponibilizam o uso de soluções tecnológicas automatizadas para aperfeiçoar todos os processos que envolvem a equipe, considerados a imensa quantidade de informações e os dados a serem preenchidos.

Para esses respondentes, os treinamentos direcionados ao uso de soluções tecnológicas que visam a dar maior agilidade e segurança aos processos internos, além de garantirem a atualização dos profissionais, também favorecem o nivelamento do conhecimento da equipe sobre o tema tratado. Facilitam o entendimento comum e a adoção de padrões de trabalho.

Os respondentes destacam que o método utilizado foi a habilitação dos colaboradores por meio de cursos de capacitação específicos. Nesse contexto, a atualização dos profissionais passou a ser uma necessidade básica, de modo a permitir que os colaboradores atuem de forma ativa e segura, sem falhas, a fim de minimizar impactos e riscos, além de garantir a aderência aos novos processos obrigatórios.

Por unanimidade, as empresas acreditam que é essencial investir em atualização e capacitação dos seus colaboradores, para garantir a formação de equipes de alto rendimento que necessitam de preparação prévia para atender às novas regras de forma correta, além de assegurar a construção da imagem e da reputação da empresa.

Assim, questionou-se se existe a utilização dos canais de comunicação interna da empresa, para manter os colaboradores atualizados, como distribuição de matérias, artigos e notícias relevantes sobre o tema, num processo contínuo de aprendizado. Os resultados são apontados na Tabela 5. 
Tabela 5

Utilização dos canais de comunicação interna da empresa

\begin{tabular}{ccc}
\hline & Entrevistados & Frequência \\
\hline $\operatorname{Sim}$ & 3 & $60 \%$ \\
Não & 2 & $40 \%$ \\
\hline
\end{tabular}

Nota. Fonte: Dados da Pesquisa.

Nota-se que, para $60 \%$ dos entrevistados, é interessante a utilização de canais de comunicação interna da empresa, para manter os colaboradores atualizados, com a distribuição de materiais, artigos, notícias relevantes, o que favorece a criação de uma cultura voltada ao desenvolvimento profissional. Conforme Tabela 5, 40\% das empresas não se utilizam de treinamentos e comunicação interna.

Questionou-se então se haviam sido realizadas contratações de serviços de terceiros, a fim de atender ao Bloco K. O resultado pode ser evidenciado na Figura 2.

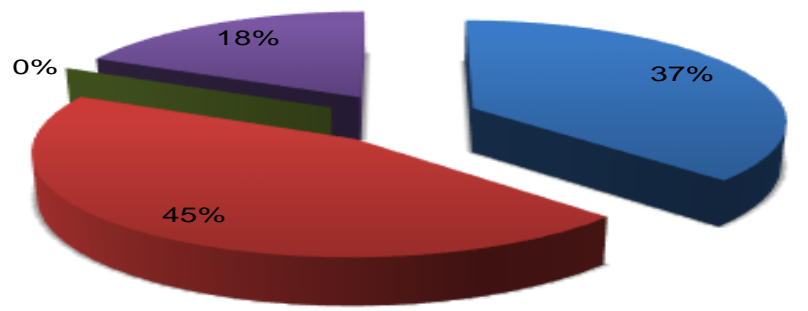

\footnotetext{
Para a Implementação de Hardware e Software

- Para Treinamento de Pessoal

Consulta Especializada

- Pessoa Para Exercer Função.
}

Figura 2. Contratação de serviços de terceiros

Fonte: Dados da pesquisa.

Nota-se que com maior frequência que realizou-se a contratação para a implementação de treinamento de pessoal que totaliza um percentual de $45 \%$. Para $37 \%$ dos entrevistados, a contratação de implementação de Hardware e Software foi de maior necessidade. $18 \%$ dos respondentes descreveu ser necessária a contratação de pessoas para exercerem a função. Nesse questionamento o respondente tinha a possibilidade de marcar mais de uma alternativa.

$\mathrm{Na}$ sequência argumentou-se que assinalassem as dificuldades encontradas para a implementação do Bloco K quanto ao controle de estoque. Da mesma forma, os respondentes poderiam assinalar mais de uma alternativa. Os resultados são evidenciados na Tabela 6.

Tabela 6

Dificuldades encontradas para a implementação do Bloco K quanto ao controle de estoque

\begin{tabular}{lcc}
\hline & Entrevistados & Frequência \\
\hline Mapeamento movimentações de estoque & 5 & $27 \%$ \\
Adequação dos softwares & 4 & $21 \%$ \\
Movimentações existentes com terceiros & 2 & $10 \%$ \\
Cultura da empresa em relação a uma equipe comprometida & 2 & $10 \%$ \\
Revisão de cadastro das mercadorias e produtos & 5 & $27 \%$ \\
Sistemas adequados para atender as exigências do SPED. & 1 & $5 \%$
\end{tabular}

Nota. Fonte: Dados da Pesquisa. 
Com base nos dados coletados pelo questionário, pode-se verificar que o mapeamento do processo produtivo, que inclui a movimentação do estoque e as perdas ou quebras dos produtos, revisão de cadastro das mercadorias e produtos e a adequação dos softwares de controle de estoques, quanto à compra e venda de produtos, são as maiores dificuldades que as empresas tiveram, ou têm, para a implantação do Bloco K.

Isso decore da complexidade que as organizações possuem com relação ao processo produtivo e que, de fato, contribui para dificultar a correta apresentação dos dados aos órgãos federativos e fiscalizadores. Os resultados vêm ao encontro das premissas apresentadas por Leão (2015) e Alves (2015), que propõem a necessidade de planejamento quanto aos processos e organização empresarial. Com base no detalhamento desses processos, viabiliza-se o ordenamento das ações internas que culminará no bom desempenho para implantação dessa ferramenta.

Por fim, buscou-se identificar por meio de pergunta aberta a existência de dificuldades encontradas, além das citadas. $20 \%$ dos entrevistados responderam que não estão enfrentando dificuldade referente à situação questionada.

Outros $60 \%$ responderam que uma das principais dificuldades que estão enfrentando está na falta de informação e capacitação por parte dos órgãos fiscalizadores quanto à realização dos procedimentos exigidos pelo Bloco K.

Esses salientaram ainda que a mudança do processo acaba sendo uma das principais dificuldades encontradas. Já os demais $20 \%$ dos entrevistados responderam que a dificuldade está ligada à situação financeira da empresa, devido à falta de recursos disponibilizados para colocar em prática esse novo processo, bem como com relação à implantação de um software adequado para prosseguir com o processo exigido pelo Bloco $\mathrm{K}$.

Com relação aos benefícios trazidos por essa exigência, verificou-se que $80 \%$ dos respondentes afirmam já haver impactos positivos, principalmente na parte de controles internos, como, por exemplo, no controle de estoques.

O terceiro respondente destaca que:

Ocorreram ajustes principalmente da parte de estoque, na digitação da quantidade de produtos, nota fiscal e tributação, se o usuário não cadastrar corretamente o sistema vai acusar erro, [...] hoje a coisa anda mais amarada, com isso busca-se e precisa-se ter um controle bom e eficaz.

Os demais $20 \%$ dos entrevistados afirmam não ter tido qualquer tipo de benefício com a implantação do Bloco K. Afirmam que na empresa já havia controle interno sobre a movimentação do estoque.

Nota-se, nesse contexto, que os resultados divergem, em parte, dos estudos de Fernandes (2015) e Jesus (2015). Ambos apontam a implantação do Bloco K como uma ferramenta que pode contribuir para a gestão tributária nas organizações. Assim, apesar de permitir maior controle dos impostos, em razão da necessidade do seu detalhamento, não se vislumbra em sua implantação a possibilidade de economia tributária.

Esta seção apresentou os dados coletados nesta pesquisa, bem como sua tabulação e análise. A seção seguinte aborda as conclusões do estudo e recomendações para estudos futuros.

\section{CONCLUSÕES}

No cenário atual fica evidenciado que a tecnologia norteia e protagoniza grandes mudanças. E essas passaram a exigir nas empresas das mais variadas áreas aperfeiçoamento quase que instantâneo.

O presente estudo teve por objetivo identificar as adaptações necessárias para implantação do Bloco K do SPED Fiscal nas empresas. Para tanto, pesquisou-se por meio de questionários aplicados ao responsável pelo setor fiscal de cada empresa, o que compõe a amostra de pesquisa. Foram enviados questionários por e-mail para seis organizações. Dessas cinco retornaram com o instrumento respondido integralmente. 
As empresas perceberam dificuldades na implantação do Bloco K no SPED. Dessas dificuldades destacam-se, por exemplo, problemas com o sistema interno, falhas de configuração, cadastros incompletos e falta de conhecimento para trabalhar com o SPED. O suporte para superação dessas dificuldades foi encontrado em cursos de capacitação.

Verificou-se que o mapeamento do processo produtivo e as movimentações de estoque foram apontados como a principal dificuldade. Essa dificuldade está ligada diretamente ao controle de estoque, que em muitos casos não é feita de forma ordenada. Outro fator importante a ser destacado é a revisão de cadastro das mercadorias e produtos. Esse acontecimento, muitas vezes, não é eficiente e exato. Acarreta o erro de contagem e, consequentemente, dificuldade na realização da entrega dos dados para o Bloco $\mathrm{K}$.

No processo de implantação as empresas precisaram investir principalmente em treinamento do pessoal envolvido e em tecnologia, softwares de gestão empresarial. Dessa forma, infere-se que o Bloco $\mathrm{K}$ trouxe maior necessidade de evolução e adequação às novas exigências e as empresas precisaram investir em conhecimento e tecnologia, que são as bases para a evolução.

Os sistemas devem estar preparados e capazes de gerar as informações com o nível de detalhamento do Bloco $\mathrm{K}$ e essas informações devem ser geradas com segurança. Os responsáveis pela área devem correr contra o tempo para que a informação possa ser transmitida de forma consistente e ser condizente com os números do balancete da empresa. Um bom sistema de gestão certamente ajudará a fazer esse controle, as empresas terão informações mais precisas sobre a sua produção, e saberão, de fato, os custos dos seus processos produtivos.

A percepção do responsável pela implantação do projeto foi determinante para obter êxito no processo de implantação e adaptação ao Bloco K. Pode-se observar destaque na base de dados existente, controles internos e capacitação dos colaboradores envolvidos no processo. Percebe-se com isso a importância de se trabalhar com os controles internos, investir em infraestrutura, para melhorar a base de dados existente na empresa.

Outros pontos de destaque são investimentos em tecnologia da informação e sistema operacional, além de melhorar e profissionalizar a equipe envolvida. Percebe-se a importância, que os entrevistados deram, em investir na sistematização da empresa com investimentos nos controles internos e com o intuito de formar uma base de dados consistente e confiável. Após a formação e manutenção dessa base de dados segura, a empresa poderá obter êxito no processo de implantação do Bloco K, além de usufruir dessa base formada, em prol do seu desempenho.

Conclui-se, mesmo considerando as dificuldades elencadas para a implantação do Bloco $\mathrm{K}$, que o sistema traz benefícios que impactam positivamente na gestão das empresas, pois fortalece o sistema de controles internos, e proporciona maior confiabilidade nas informações geradas. Esse resultado reforça a importância da empresa estar se aperfeiçoando ao máximo, investindo em conhecimento e tecnologia, para estar preparada para a evolução.

$\mathrm{O}$ Bloco $\mathrm{K}$ remete a trabalhar com prevenção e controle de perdas das mais diversas origens, possibilitadas pela falta de controle mais rigoroso. O custo dessa adequação e a implantação dessa obrigatoriedade serão menores se comparados aos benefícios a organização da empresa, fornecendo assim uma ferramenta de controle.

O Bloco K deve ser visto como uma oportunidade de negócio e deixado de ser encarado como uma nova obrigação imposta pelo fisco para as empresas.

Como limitações do estudo destaca-se que, em razão da diversidade tributária aplicável aos estados, os resultados não podem ser generalizados. Outra limitação está na quantidade de entrevistados, o que pode gerar algumas distorções nos resultados e nas análises.

Recomenda-se, para futuros trabalhos, observados os resultados obtidos, que pesquisas nessa área sejam contínuas. Assim, apresentam-se como sugestões para próximos trabalhos enfocando o Bloco K:

- Reaplicar o questionário em uma maior amostragem;

- Realizar um estudo a partir do momento em que todas as empresas estiverem enquadradas no Bloco K;

- Realizar um estudo sobre a adequação e compatibilidade dos sistemas de informação quanto à implantação do Bloco K;

- Realizar um estudo para verificar os benefícios que o SPED trouxe para as empresas. 


\section{REFERÊNCIAS}

Ajuste Sinief Confaz 17, 21 de outubro de 2014. (2014). Despacho do secretário Executivo. Recuperado de http://www1.fazenda.gov.br/confaz/confaz/atos/despacho/ 2014/dp195_14.htm

Ajuste Sinief Confaz 18, 18 de outubro de 2013. (2013). Recuperado de http://www.normaslegais.com.br/legislacao/ajuste-sinief-18-2013.htm

Ajuste Sinief Confaz 8, de 2 de outubro de 2015. (2015). Recuperado de https://www. confaz.fazenda.gov.br/legislacao/ajustes/2015/aj_008_15

Alves, C. R. (2015). Artigo - Bloco K - EFD ICMS/IPI. Recuperado de http://crcgo.org.br/novo/ wp-content/uploads/2015/04/BlocoK.pdf

Bompan, F. (2015). Bloco K do S SPED Fiscal, empresas terão que enviar controle e produção e de estoque. Recuperado de http://www.acesaovicente.com.br/noticias

Bompan, F. (2015). SPED ainda gera dúvidas e preocupa empresários do país. Recuperado de http://www.martinsalves.com.br/noticias/autor/fernanda-bompan/pagina/2.html

Cooper, D. R., \& Schindler, P. S. (2011). Métodos de pesquisa em administração (10a ed.). Porto Alegre: Bookman.

Cruz, S. M. S. da, Librelotto, L. I., Ferroli, P. C., Bonatti, C. A., \& Zanin, R. F. (1998). Gerenciamento dos sistemas de informação. Anais do Encontro Nacional de Engenharia de Produção. Recuperado de http://www.abepro.org.br/biblioteca/ENEGEP1998_ART462.pdf

Decreto $n^{\circ}$ 6022, de 22 de Janeiro de 2007. (2007). Institui o Sistema Público de Escrituração Digital - Sped. Recuperado de http://www.planalto.gov.br/ccivil_03/_ato20072010/2007/Decreto/D6022.htm

Fernandes, E. (2015). Bloco K: Uma visão integrada. 2015. Recuperado de http://alfonsin.com.br/bloco-k-uma-viso-integrada

Gil, A. C. (2010). Como elaborar projetos de Pesquisa (4a ed.). São Paulo: Atlas.

Gomes, M. S. (2014). Ressurreição do Livro Modelo 3 (Bloco K). Recuperado de http://fernandesfigueiredo.com.br/ressurreicao-do-livro-modelo-3-bloco-k/

Jesus, J. L. F. (2015). SPED Fiscal - Empresas terão que enviar Controle da Produção e de Estoque. Recuperado de http://www.confirp.com.br/sped-fiscal-empresas-terao-queenviar-controle-da-producao-e-de-estoque/

Joaquim Filho, J. (2015). Programas SPED - Penalidades Promovidas pela Lei $n^{\circ}$ 12.766/12. Recuperado de: http://www.contabeis.com.br/artigos/1126/programas-sped-penalidadespromovidas-pela-lei-1276612

Leão, T. (2016). Bloco K do SPED Fiscal: entenda o que é, para que serve e prepare-se. Recuperado de http://www.nomus.com.br/blog-industrial/2015/06/bloco-k-do-sped-fiscalentenda-o-que-e-para-que-serve/\#sthash.Jb3kw6pm.dpuf

Lei $n^{\circ}$ 12.766, de 27 dezembro de 2012. (2012). Recuperado de http://www.planalto. gov.br/ccivil_03/_ato2011-2014/2012/lei/l12766.htm

Maciel, E. (2015). Instrução Normativa SRF $n^{\circ}$ 86, de 22 de outubro de 2001 comentada. Recuperado de https://www.legisweb.com.br/legislacao/?id=75073

Marconi, M. A., \& Lakatos, E. M. (2009). Técnicas de Pesquisa (4a ed.). São Paulo: Atlas.

Martins, E. (2015). Bloco K do SPED é prorrogado para 2016. Publicado 21 de outubro de 2015. Recuperado de http://edmilsonmartins.com/tags/bloco-k/

Oliveira, F. (2014). Empresas ainda não estão preparadas para o Bloco K, do Sped. Jornal Contábil. 
Passos, G. R. P. (2010). SPED - Sistema Público de Escrituração Digital: um novo paradigma em termos de conformidade tributária. Dissertação de Mestrado, Fundação Escola de Comércio Álvares Penteado.

Receita Federal do Brasil. (2015). SPED: Sistema Público de Escrituração Digital. Recuperado de http://www1.receita.fazenda.gov.br/sistemas/sped-fiscal/o-que-e.htm

Richardson, R. J. (1999). Pesquisa Social: métodos e técnicas (3a ed.). São Paulo: Atlas.

Rocha, C. (2012). Contabilidade de Custos. São Paulo: Editora IOB.

Rocha, C. A., \& Almeida, C. B. S. (2014). Bloco H e Bloco K: Aspectos teóricos e práticos (1a ed.). São Paulo: lobstore.

Somasundaram, G., \& Shrivastava, A. (2011). Armazenamento e gerenciamento de informações: como armazenar, gerenciar e proteger informações digitais. Bookman: São Paulo.

Sped Brasil. (2015). Recuperado de www.spedbrasil.net

Young, L. H. B. (2009). SPED - Sistema Público de Escrituração Digital. Curitiba: Juruá. 